\title{
The Blameworthiness of Health and Safety Rule Violations*
}

\author{
PETER MASCINI
}

\begin{abstract}
Man-made disasters usually lead to the tightening of safety regulations, because rule breaking is seen as a major cause of them. This reaction is based on the assumptions that the safety rules are good and that the rule-breakers are wrong. The reasons the personnel of a coke factory gave for breaking rules raise doubt about the tenability of these assumptions. It is unlikely that this result would have been achieved on the basis of a disaster evaluation, or high-reliability theory. In both approaches, knowledge of the consequences of human conduct hinders an unprejudiced judgement about where the blame for rule breaking lies.
\end{abstract}

\section{INTRODUCTION}

Immediately after a man-made disaster has taken place, journalists, politicians, policymakers, and scientists ask how it could have happened, and how similar failures can be avoided in the future. Very often part of the answer to the first question is that the breaking of safety rules contributed to the accident. The radiation accident that took place in a nuclear plant in the Japanese village Tokai in 1999, resulting in forty-nine casualties, provides an example of this reaction. It was concluded that this accident would not have happened if the employees had followed the official rule to transport uranium through pipes, instead of pouring it into a petrol tank with a bucket (Van der Lugt 1999). Another example concerns the disaster that took place in 2000 in a fireworks warehouse in the Dutch city of Enschede. This disaster resulted in the deaths of twenty-two people. In this case, the use of illegal storage containers and trade in illegal fireworks were identified as the main causes of this explosion (Oosting 2001).

If the answer to the first question is that the breaking of rules contributed to an accident, the almost automatic answer to the second question is that

\footnotetext{
* This paper was presented at the conference, "Risk in its Social Contexts," held at the University of Plymouth, United Kingdom, 8-9 September 2003.

Address correspondence to Peter Mascini, Erasmus Universiteit Rotterdam, Faculteit Sociale Wetenschappen, kamer M6-06, Postbus 1738, 3000 DR Rotterdam, The Netherlands. E-mail; Mascini@fsw.eur.nl.
} 
inspections regarding compliance with the rules must be intensified, and that sanctions for breaking them must be increased. Such measures are often proposed by the most powerful political leaders following a disaster. President Bill Clinton did precisely that after the disaster with TWA's Boeing 747 in 1996 (Eijsvogel 1996), and Prime Minister John Major also did it in 1997, when it became known that the Ministry of Agriculture had repeatedly ignored emergency signals of abuses in British abbatoirs (Wittenberg 1997). In The Netherlands the chairman of the Oosting Committee even advocated a "cultural revolution" within the entire public administration, after the aforementioned explosion in the Enschede fireworks warehouse, and a fire in a bar in Volendam on New Years Eve 2001 that killed thirteen teenagers and wounded around two hundred and fifty more. After both disasters, each evaluation committee concluded that the administration had systematically turned a blind eye to rule violations (Alders 2001; Oosting 2001).

On the one hand, the more or less automatic reflex to tighten the enforcement of the rules is understandable. It gives a clear signal to the victims and citizens that disasters are taken seriously and that authorities act strongly in response to them. In this way, the authorities responsible try to restore the loss of faith among the population. As such, this measure has an important symbolic meaning. On the other hand, this measure also raises an important question. Namely, it presupposes that the individuals involved with these rule violations should have known that sooner or later, there would be an accident, and that they ought to have taken this knowledge into account. In other words: the safety rules were good and could be complied with, and the violators of the rules were wrong. This article deals with the question of whether this accusation is always justified. One can doubt this because it is often the people who are supposed to be protected by the rules who break those rules. So, in other words, it is assumed that the people involved in the incident are either always free to comply with the rules, or take a calculated risk when breaking them. Our aim is to find out whether this assumption is correct.

This aim has both moral and instrumental implications. If rule violations cannot automatically be labeled as human errors, it raises the question of whether the rule-breakers can be blamed automatically, and whether increased enforcement of safety rules is always an effective measure for the prevention of man-made disasters.

The answer to the research question is based primarily on a qualitative case study of a Dutch coke factory. This factory is a business unit of a multinational. Operators work with inflammable, explosive, and harmful chemicals, and with powerful machinery. They do heavy and dirty work under unpleasant weather conditions. During the last two decades of the last century, there have been hundreds of incidents at the factory, varying in severity from a bruised ankle caused by stepping on a piece of coke to two casualties as a result of falls from great height. Other serious wounds resulted, for example, from a short circuit in an electricity closet, an exploding starting motor, and 
a fall into a tank filled with caustic soda. There have also been several very dangerous situations that could easily have caused serious accidents. For example, a large part of the gas-cleaning section burned down, and a huge ventilator flew over a dune top after it broke off. These events demonstrate that the wrong decisions in the coke factory can have very serious consequences for the workforce and their surroundings. Nevertheless, rules were broken regularly. The reasons given by the operators for deviating from safety rules were analyzed, in order to determine whether these acts could be labeled as human errors automatically. The case study is complemented by additional data, which illustrate that the findings are not unique to the coke factory.

\section{RISKS AND FACTS}

I will evaluate rule violations in terms of the reasons given by employees for breaking those rules, and not, as is usually the case with respect to manmade disasters, in terms of the effects of rule breaking. This is a deliberate choice. Rule breaking is automatically condemned in disaster evaluations simply because they have led to an accident. The fact that an accident has taken place is asserted as the undeniable proof that the violation was a human error. This argument may seem conclusive, but in fact, is not. The fundamental problem connected with the judgment of human conduct following disasters was put forward by Turner in 1976. He criticized the official evaluation reports of three industrial disasters, on which his own analysis is based. In his opinion, these three reports are problematic because they do not take into account the fact that the situation before the disaster was significantly less clear for the people involved than was concluded afterwards:

Each [report] dealt with the problem that caused the disaster as it was later revealed and not as it presented itself to those involved beforehand. The recommendations, therefore, treat the well-structured problem defined and revealed by the disaster, rather than the pre-existing, ill-structured problems.

(Turner 1976: 393)

In his article (Tumer 1976), describes a model consisting of different phases in relation to the failure of foresight, which he developed more thoroughly in his monograph Man-made Disasters (Turner 1978). In the first phase of his model, "the way the world is thought to operate" synchronizes with "some true state of affairs." During the second phase, the "incubation phase," perception increasingly deviates from reality. This eventually results in a disaster. Finally, this disaster results in a situation in which people obtain an accurate perception of reality again. According to Gephart (1984), the risk of overestimating human errors is also inherent to this model. That is, it is only possible to decide which risks were overlooked or denied afterwards. According to Gephart, the people involved are confronted with hard-to-interpret, often contradictory messages and interests, in such a way 
that their perception of reality can only be labeled as wrong on the basis of after-the-fact knowledge:

Communication problems and unheeded warnings conceived by Turner as central to the pre-onset stages are actually only seen in retrospect (Perrow 1981). They are present in all disasters and in a variety of non-disasters as well. Considerable noise blends with potential warning signals to mask the warnings; they are distinguishable from normal signals and false warnings only after the fact. (Gephart 1984: 211)

The only, and justified, reply that Pidgeon and Turner (1997: 175) give to this criticism, in the revised and enlarged second edition of Turner's ManMade Disasters, is that it is not relevant for the phase model exclusively, but more generally to all post hoc case studies of man-made disasters. ${ }^{1}$

Vaughan (1996) has convincingly demonstrated that the overestimation of human errors as a result of the reconstruction of disasters is not just a theoretical problem, on the basis of research into the cause of the explosion of the space shuttle Challenger in 1986. The television images of this disaster, leading to the death of all seven crew members-including primary school teacher Christa McAucliffe, who was to promote this journey by teaching about it - are undoubtedly still remembered vividly by many. Vaughan demonstrates that the dominant explanation for this disaster was completely wrong. The dominant interpretation was that the Challenger exploded because of individual errors and managers violating crucial safety rules in their quest for profit. She concludes that it was conformity to the dominant culture rather than deviation from it that led to the disaster. One of the most important causes of the accident was that the importance of scientific proof was stuck to for too long. Consequently, the vague suggestion that low temperatures were causing problems with the O-rings of the rocket boosters were not taken seriously. In fact, this proved to be the direct cause of the disaster.

Vaughan could only draw this conclusion because she tried "to forget" that the disaster took place. She did this by limiting her analyses mainly to documents concerning decisions made before the disaster. This method made it possible for her to imagine how the people involved had defined the situation at that time. According to Vaughan, their definition of the situation shows clearly that the accusations that followed the disaster are totally unjustified. This is the reason that she cites Starbuck and Milliken with approval, concluding that "retrospective analysis of bad organizational outcomes tends to focus attention selectively on the road not taken that might have altered the outcome" (Vaughan 1996: 253). One inherent problem with evaluation research into man-made disasters is thus that the people involved are judged on the basis of the knowledge that their conduct has had serious consequences, while by definition, they could not be certain about this themselves. This is why, in this kind of research, there is always a danger that the possibilities for the people involved to prevent the accident-for example, by complying with the safety rules - are overestimated. 
Is it easier to evaluate human conduct objectively by analyzing socio-technical systems that did not cause any disaster, as is done by researchers working on the so-called high-reliability theory? (see, for example, La Porte 1994; La Porte \& Rochlin 1994; Roberts 1990, 1993; Roberts, Rousseau \& La Porte 1994; Schulman 1993: Weick 1987; Weick \& Roberts 1993; Weick, Sutcliffe \& Obstfeld 1999). The answer is no. Before substantiating this answer, I will summarize the content of the high-reliability theory. This theory is supposed to explain why socio-technical systems, mostly American aircraft carriers, have remained accident free. The explanation is short: because they carry out an effective policy to prevent these accidents. Sagan (1993: 17) sums up the four policy characteristics that would determine the accident-free status of highly reliable socio-technical systems: (i) ability to learn from mistakes, (ii) presence of political leaders and managers giving the highest priority to the safety and reliability of installations, (iii) high levels of availability-back-upsof personnel and technical safety devices, and (iv) a "high reliability culture," consisting of decentralized and consistently executed procedures.

It is not a coincidence that the explanation for the absence of accidents given by high-reliability theory only refers to policy. This theory seems to presuppose that the fact that accidents have not taken place proves that human conduct has been effective. However, this presupposition lacks empirical foundation. The reason for this is that high-reliability theory is limited to socio-technical systems that have remained accident-free so far:

If we only examine systems without failures, as the "High-Reliability Theory" are prone to do, we are "selecting on the dependent variable", that is, examining favorable outcomes only and then predicting what brought them about. (Perrow 1994: 214)

There is no systematic comparison of the accident rates of organizations that do and do not satisfy the four policy characteristics. The first consequence of this is that other causes of the accident-free status of the systems under scrutiny, which are not the result of human conduct-for example, coincidence-are, incorrectly, not taken into consideration. It has been demonstrated, for example, that nuclear military complexes have never caused a major accident, although they do not have all the characteristics of reliable organizations (Bourrier 1996: 105; Sagan 1993). The possibility that these systems have remained accident free, in spite of the actual policy, is overlooked altogether (cf. Weick 1997: 399). However, this cannot be ruled out beforehand. Perrow (1984), Wildavsky (1988) and Sagan (1998), for example, argue that redundancy is a source of risk rather than a source of success. Weick (1998: 73) and Pidgeon (1998: 100) do the same with a homogeneous (safety) culture because it excludes deviant views. So, while accident research has a tendency to judge human conduct too severely, high-reliability theory tends to be too positive about it.

This means that the chance of an incorrect evaluation of human conduct is inextricably bound up with both accident research and high-reliability 
theory. The knowledge that an accident has taken place pushes researchers in the direction of the verdict that the people involved should have anticipated the disastrous consequences of their behavior. The knowledge that a certain branch of industry has remained accident-free can easily lead to human errors being overlooked. Researchers of man-made disasters tend to overestimate human errors, while researchers who make use of high-reliability theory run the risk of underestimating them. The problematic similarity of both types of research is that explanations are sought for events that have already happened. In the former case, they look for causes of accidents, and in the latter for why there has been an absence of accidents. This is why I evaluate rule violations according to the risks that accompany them, instead of their actual consequences. The people involved act in uncertainty about the consequences of their conduct and ought to be judged accordingly. This means that my analysis concentrates on the chance of an accident, and not, as in the other two research approaches, on the certainty of an accident or the absence of it. The point of departure of this analysis is that employees who deliberately take risks, even though they are not hampered from not doing so, are blameworthy. One cannot automatically speak of a human error if either one or both conditions are not met.

\section{COLLECTION OF THE DATA AND DESCRIPTION OF THE CASE}

The coke factory is located with ten other factories on industrial land in the Netherlands. The central Health and Safety department helped me to gain admittance to this factory. A member of this department asked which of the five factories in the "steel section" wanted to participate in my research. The main reason given by the management of the coke factory for volunteering was that they wanted to know more about the causes of accidents. The accident ratio of this factory had remained above average, despite heavy investments in health and safety. Management wanted to know why.

I collected the data for my Ph.D. project on the handling of health risks (1999) on two occasions, 1995 and 1998. During the first period of data collection, I accompanied different work shifts during their operations and attended their meetings for one month. During conversations, I asked employees which risks they were exposed to, what they themselves or the organization did to control these risks, and what else should be done to improve risk management. I also asked about the making and applying of risk management instruments such as inspections, regulations, and accident reports. This helped me to find out how these instruments worked out in practice.

In the second round of data collection, I surveyed a cross-section of personnel. One hundred and four employees gave written responses to a questionnaire, and 69 were interviewed. All operational personnel and managers occupied in the production and maintenance department were asked to take part in 
the survey. The response rate was 72 percent. The majority of the nonresponses consisted of employees who were not able to respond because of illness, absence, or insufficient mastery of the Dutch language. The questions in the survey concerned the priority given to health and safety, and the intensity and the style of influencing others or being influenced by others, with regard to risk management. In all interviews, respondents were asked to give specific examples of influence attempts. Many of these examples related to the handling of safety rules. The interview fragments given below were translated from Dutch into English.

At the time of data collection, a permanent staff of about 270 worked in the factory, divided between the production, maintenance, and technology departments. I labeled the management and the shift supervisors of the coke factory as middle management because they were subordinated to the board of directors of the overall concern. Middle management was responsible for the implementation of company policy and for daily management. Although middle management predominantly enforced safety regulations, it occasionally had to comply with the rules as well. They had to comply with general safety rules when they physically went into the factory, and with more specific rules when they were involved in operational tasks. Operational personnel also shared responsibility for enforcing health and safety rules. It was their formal duty to report dangerous situations, such as the violation of health and safety rules by colleagues and superiors. However, most of the time, operational personnel just had to comply with the rules. This means that both middle management and operational personnel were responsible for enforcement as well as for compliance, although the priority for enforcement lay with middle management, and for compliance with operational personnel.

\section{RESULTS: THREE TYPES OF RULE VIOLATIONS}

The bulk of the numerous safety rules of the factory are complied with without hesitation. This is done with considerable effort and expenditure, including the purchase and use of personnel protection devices, the registration of permits to work inside the factory, working according to regular procedures, reporting operations, and conducting health and safety audits. The employees not only usually comply with the rules because they think of them as useful, but also because they give a very high priority to healthy and safe production. In the survey, staff were asked how important healthy and safe production is in relation to seven other goals. The average score was 4.6 on a scale ranging from 1 (least important goal) to 5 (most important goal). ${ }^{2}$ Their reasons for attaching so much importance to this goal are; the ample availability of scientific knowledge about industrial risks, the low tolerance for these risks in society, and the tight laws to qualify for social benefits for illness or disability. However, employees regularly break rules. What is the reason for this, and to what extent can these acts be 
labeled as human error? I have found three kinds of reasons for breaking the rules, that differ in the extent to which they are blameworthy.

\section{A. TOO MUCH EFFORT OR TOO MUCH TROUBLE}

The first reason for breaking rules is taking a deliberate risk because complying requires too much trouble or effort. Hutter (2001: 241) also found that "'taking the easiest and most convenient' option" is a common explanation given by the workforce of British Rail for non-compliance. One example from the coke factory that illustrates this kind of violation concerns a mechanic repairman:

Respondent: Whenever I think, "Oh dear, and now I might have to do overtime", then I think, "Screw it". . . Then I do it secretly you see. . . Then I think, "They don't see it anyhow'.". . .

Interviewer: Can you give an example of this?

Respondent: ...Well, in the hall with the gas pipes. We were working on oven twenty-one. At a certain moment we had to remove a closing valve. So I had a working permit with me and fire hoses and two fire extinguishers. You see, we thought we were ready and we went on with oven twenty-three. We dropped the fire stuff, fire extinguishers and all, but then we had to get back to oven twenty-one. We still had to grind two bolts. I say to my buddy, "I am not going to drag all this shit back, so leave it here." So then I went back just like that. I thought, "Nobody will come anyhow". I say to my buddy, "You go and watch out, and I will grind in a hurry." Well, that's what I call quick and secretly. That's what I said just before, you know. You do it because of the danger of fire, gas danger.

Interviewer: I see. You ground when the fire stuff was not there?

Respondent: Right. We had been busy there just before.

Interviewer: And then you had forgotten those two bolts?

Respondent: Right, and then we thought, "Shit, quickly those other two bolts." Before you realize it, you are busy for yet another half an hour. You have to empty the hose, you have to wind it up totally, you have to bring it there, you have to go back and forth three times. Then you think, "Let's do it quickly," and that's what I call secretly, you know, because if someone sees it, you're in trouble.

(Mechanic repairman)

It is easy for an outsider to underestimate the nuisance certain safety devices can cause in practice. For example: protective fire clothes can cause overheating during operations at the top of ovens that are already hot, the use of safety spectacles is a nuisance for some people who normally do not wear spectacles, stiff pigskin gloves cause blisters during cleaning operations, and lack of ventilation in so-called airstream helmets gives certain people a headache. In addition, it is also not easy for an outsider to realize how much effort it takes to comply with every safety rule consistently. Staff have to walk long distances repeatedly to get forms signed, order a tower wagon at the right time to be able to work safely at great height, wait for the approval of an inspector before climbing scaffoldings, and so on. From this point of view, it is understandable that personnel sometimes take a risk to avoid the nuisance 
or the effort that goes with systematic compliance with all the rules. However, although this type of violation is understandable, it does not exonerate those who break rules; on the contrary. They take a risk deliberately, even though there is nothing forcing them to take the risk. If these violations result in an accident, the people who violated the rules can be blamed for it.

\section{B. DILEMMAS}

It is less easy to condemn the second type of rule breaking. This is when people know that it increases the chance on an accident, but are obstructed from complying. In these cases, one is forced to choose between two evils. Why so? Formally, production should not undermine safety in the coke factory. This rule is more than just words. Management definitely makes an effort to put this rule into practice. However, it is the case that superiors tell their subordinates to make exceptions to the rules if the continuation of the production process is in danger. A mechanical inspector gave an example of this type of violation. He says that he has to comply with all regulations during planned, weekday activities, while he was told to deviate when an urgent problem occurred:

Respondent: Look: as soon as you see the production process is troubled, then all of a sudden a lot of things can be done without consideration of the safety rules. When we weld in the gas cleaning side, we have to have a working permit, need to have fire extinguishers present, and have to take a carbon monoxide sample. Once something went wrong and then only a sample was taken. We didn't have a working permit, and we could get going just the same. Then I think to myself: "Well, why could it go so fast that time," because then you can get started within ten minutes, "and why, on a weekday, does all of this have to happen with forms and stuff?" There are boys who really carry such a big pile of paper every week. Then I think to myself: "Well, guys, it's a nice system, but it just doesn't work."

Interviewer: And what was your reaction at that time?

Respondent: At that moment, you just get started, of course. Look, and when you bring it up, then it's sort of laughed about. And that's logical, because you're attacking people [supervisors] on things. They, of course, try to make a joke of it, but still it's not the way, of course. And I repeat: then it is possible, but if you come normally during the week, then it isn't possible.

(Mechanical inspector)

Operational personnel usually do what they are told, even though this means that they have to break the safety rules. Some of them do so because they agree that complying with all the rules is not as important as meeting the production targets. Others do so under pressure from their superiors. The reason for this is that superiors rarely accept the refusal of a subordinate to execute an illegal assignment; they would carry it out themselves or give it to another subordinate instead. In the first case, it happens that superiors put pressure on the refusing person not to make it publicly known. From 
the point of view of their stronger hierarchical position, this is a kind of blackmail. An operator gives an example of this kind of pressure:

Respondent: I've seen it happen that slopes were piled up with cokes due to production difficulties. A fire developed on top of the slopes which I had to put out. I couldn't reach it because the jet only goes so far. So I'm standing outside the fence putting out the fire and soon someone from middle management approaches, takes the water pipe away from me, climbs on top of the fence, and stands like this to reach only one meter further. Then I said: "Well, that's really safe" and he says: "You've seen nothing, or else you have to put it out yourself." Then I said: "I saw nothing if that's what you want."

I could have argued with him then, but that wouldn't have done any good. ... And because he's a boss, it gets a bit difficult. They say they don't let that influence them, but,...

Interviewer: You noticed that [the manager abused his position]?

Respondent: Absolutely. Of course, but that's only natural. If you have the chance to get even with someone who has made a fool out of you, you do it.

(Operator)

Executives who give a refused assignment to another subordinate will normally opt for sarcasm instead of blackmail. In this case, blackmail to maintain secrecy is not evident, because it is not only the person who refused who is aware of the illegal assignment, but also the next person, who gets the assignment. The first aim of emphasizing publicly that someone has exaggerated the risks connected to the refused assignment is to legitimize their own behavior. The second aim is to discourage people from refusing similar assignments in the future. In the next interview extract, an operator gives an example of a situation in which his shift supervisor made it public that he exaggerated when he refused to descend in a scaffold tank into a large generator:

Interviewer: You have mentioned that middle management example twice alreadythat they wanted you to do certain tasks. Can you tell me what that was?

Respondent: I'm willing to tell you about that example, but I think it has happened several times. I don't know if you know anything about the biological cleaner. There you've got the two big generators filled with water. That's the new bio. The water was emptied from this tank. Then a steel scaffold pipe had to be taken out from the bottom at about seven meters. A crane operator was present, but he didn't have a tank to lower a person in, no crane tank. Then my shift supervisor told me: "Then we'll take a scaffold tank that has those scaffold pipes in them and then we'll stand in that." I refused to do that and then he did it himself in that manner, even though the crane operator also indicated he wouldn't take that responsibility. And that wasn't even the worst part. Afterwards, I often enough had to hear: "Yes, but I did get it out alright, didn't I?" Then I think: "Your reaction is stupid because you created an unsafe situation and then you try to congratulate yourself afterwards." (Operator)

This means that employees who are ordered to violate safety rules to prevent loss of production face an awkward dilemma. If they refuse to execute these assignments, or if they make them public, then there is a real chance that 
their superior will punish them for it. If they carry out the assignment, then they will probably be blamed for it if something goes wrong (cf. Fischer 1993). The trial over the death of ten mineworkers in Austria after a lime mine collapsed is a clear example of this (Jusek 2000). The manager who ignored safety measures for years because of profit seeking was one of the accused. He said he acted the way he did because the owner of the mine, Luzenac, wanted higher profits. Now the prosecutor has sued the manager because his decisions caused a disaster. However, if he had complied strictly with the rules, his employer would have punished him for that. This means he was hampered from complying with the rules. Although the pressure is less, the same holds for the employees in the coke factory who ignore safety measures because their superiors tell them to do so.

The choice between production and safety is not the only dilemma that confronts personnel in practice (cf. Hutter 2001: 244). De Koning and De Vries (2001) show this in their research initiated after the fire in the Dutch town Volendam on New Years Eve 2001. They studied the compliance with fire regulations by the catering industry in five Dutch towns. The owner of a bar made it clear that local authorities apply conflicting regulations: "The fire brigade says: garbage has to be put outdoors, because inside it is a risk. But refuse collection says: outside is not allowed, because it pollutes the street; keep it indoors." In this same study, an inspector noted that the door of an establishment opens to the inside, which can cause a concentration of people during panic situations, making it impossible to open the door. However, a door that opens in the "escape direction" leads to the public road, and this is not allowed. In these cases, it is impossible to make an unproblematic choice because of contradicting rules. Rasmussen, Duncan and Leplat (1988) have shown that the lengthy execution of repetitive labor also unavoidably results in human errors.

This leads to the conclusion that the more someone is obstructed from complying with the rules, the more problematic it is to speak of human error. In other words: without a clear structure supporting and encouraging moral behavior, it is unfair to blame employees when they do not conform (cf. Bovens 1998).

\section{C. "IMPOSSIBLE" RULES}

The third reason for breaking safety rules, is with what employees call "foolish" or "impossible" rules. These concern prescriptions thought of as too general, far-fetched, or simply counterproductive in certain situations. This type of violation differs fundamentally from the other two, because in this instance, employees do not accept that violation of the rule is risky. This is also the type of rule violation that I have most frequently encountered. Hutter (2001: 244) also found that no less than 31 percent of the workforce of British Rail regarded safety equipment and occupational health and safety regulations as a hindrance instead as a help. A mechanic repairman of the coke factory puts this argument into words as follows: 
Respondent: You must finish a job within a certain amount of time all the same, but still you have to take care that it is done safely, but this does not mean that you have to use all safety instruments available. It can also be done safely in other ways. . . Many roads lead to Rome. There are also several ways to do it safely. And if you do everything according to the safety measures, you are busy one hour dragging around safety devices, while the job only takes five minutes. Then you can also do it with less, ah,...

Interviewer: Could you give an example of this?

Respondent: Suppose that you have to weld something on the side where the gas is cleaned. First I have to pick up a fire form, then I have to get fire extinguishers, and then I have to get gear. I am busy for about half an hour. For a job that takes two or three minutes at the most. Then I say, "Fetch a fire hose and it will work out just fine as well."

Interviewer: I see. A fire hose instead of $a, \ldots$ ?

Respondent: Yes, because they are present at that spot already. And I think that I am working safely as well, because if something happens, I can extinguish it.

(Repairman)

The fact that the workers do not perceive risks when they break the rules does, of course, not mean that there are actually no risks involved. It is well known that employees who are exposed to risks constantly get blind to these risks or deny them in order to reduce cognitive dissonance. An extreme example of this concerns steel workers on skyscrapers, who totally black out the life-threatening dangers of their work in order to control their fears (Haas 1977). It can be argued that employees who violate rules because they think it is not dangerous, while in fact it is, make human errors.

In order to find out whether this was the case in the coke factory, it was important to find out what the middle management thought of the breaking of "impossible" rules by their subordinates. Supervisors are less likely to get blind to the risks, because they seldom carry out the tasks to which the rules apply. So, opposition of management to the practice of their subordinates may indicate that operational personnel do take risks when they break "impossible" rules, although they do not perceive them.

Indeed, middle management is usually strongly opposed to this practice by their subordinates. Management not allowing operational personnel to make exceptions to the rules generates many differences of opinion. These differences of opinion arise in all kinds of situations: working at great height without a safety harness, transporting high-temperature chemical products with rubber hoses instead of steel pipes, going in front of a large machine when you ought to climb over it, and working in the neighborhood of a running conveyor belt. They also take place in different phases of the work: while handing out assignments, during the supervision of operations, and during meetings where the implementation or adaptation of procedures and safety rules is on the agenda. These differences of opinion are not restricted to the coke factory either. It is common for so-called "street-level bureaucrats" to argue that formal rules fit in badly with the specific circumstances to which they apply. Management does not want employees to take these circumstances into account 
because it obstructs uniform decision-making (see, for example, Lipsky 1980). However, there are reasons why the denial of supervisors does not automatically imply that operational personnel knowingly take risks when breaking "impossible" rules.

First, sometimes the perception of risks is not one of the reasons why middle managers refuse to allow their subordinates to make exceptions to the rules. Other reasons include the fact that they do not want to generate discussions after creating precedents, or that they want to avoid the possibility of being held responsible for accidents resulting from rule violations that they have allowed. Therefore, sometimes middle managers refuse to allow the breaking of "impossible" rules, even though they do not perceive any risks in doing so.

Second, and more important, is that management apply double standards. They often perceive risks when subordinates violate the rules, but not when they themselves execute the tasks to which the rules apply. This can happen when supervisors have to perform inspections inside the factory, or when they have to help solving problems. Some of the managers who execute tasks break rules themselves, while they do not allow their subordinates to do so. A shipping supervisor illustrates this in the next extract:

\footnotetext{
Respondent: I think I often avoid certain things because I have been around for such a long time, and I know how it can be done safely as well. I'm talking about the fuel system now. We [shipping department supervisors; PM] always say to the boys: "If you go to the program, turn off the gas pipes." For myself, if I have to do something there, I don't always turn them off because I know what to do the minute something goes wrong. If a battery just disgassed, then I know it takes twenty minutes for it to switch to gas again. So, I have twenty minutes to do as I please, without having to turn off the tap. And if it switches back on suddenly, God forbid, then I know what to do. . . But to the boys I always say: "Always turn that thing off."

Interviewer: Aren't you ever called to account for not turning the thing off yourself and always ordering them to do it?

Respondent: No, because whenever the two of us walk there, I let the other one do the operations the way they have to do it.

Interviewer: So, they can't see it when you don't do it yourself?

Respondent: No, and I myself think that there isn't any risk in that because I know damn well what I'm doing, and when I have to do those operations, I think I do the rest of it according to the formal procedure. Because I don't do it on a daily basis, I also have to think about what I have to do.

(Shipping supervisor)
}

Other managers who execute tasks do comply with the rules, but not because they think this is safest. They do so because they believe they have to set an example for their subordinates. Supervisors know that it frustrates their subordinates when they tell them to comply with "impossible" rules. They want to preclude it from becoming harder to address subordinates who violate rules because they themselves do not comply (cf. Hutter 2001: 250). In the next extract, a shift supervisor expresses the wish to secure authority by complying with rules he in fact thinks of as superfluous: 
Respondent: If I miss out just a little bit once and they see it, then they really exert pressure on me: "You weren't doing the right thing there either. You see, if the production gets into hot water then,... " As a shift supervisor, you are treading on eggs. If there's a malfunction somewhere or somewhere something is hanging loose. I don't have a fear of heights, so I climb on top of everything and everywhere. That makes no difference to me.

Interviewer: Would you please give me an example of something that actually happened?

Respondent: I can do that. We had a malfunction at the coke side: a cylinder had broken off and the wind was blowing hard. It must have been force-seven winds, and we stood on top of that installation and then we crawled over a fence and there we stood on top of that installation where we had to lean forward a bit. You do that without actually taking notice and then later: "You were acting stupid and dangerous and this and that." Afterwards I agree with them. Then I say: "You've got a point there." I won't do it anymore. Then you're a production man again like: "Well, damned, that installation has stopped and we've got to produce again," and as far as that is concerned, we've had that Du Pont course. [The chemical concern Du Pont sells their safety policy to other companies] Then you first count to ten: "Then they'll just have to wait a second." First you collect a safety belt and only then do I go there. In your heart, you find it a bit of a comedy sometimes, but you have to set the right example. . . By virtue of my function, I have a role model function, and so I will do it sooner, while thinking to myself: "I can also do it like that," but you don't do that anymore then.

(Shift supervisor)

This finding shows that operational personnel are not the only ones who do not perceive risks when they break "impossible" rules. The same holds true for the managers who occasionally execute the tasks to which the safety rules apply. Logically, this can mean two things.

First, they are both wrong, because the execution of tasks leads to a false sense of security. It is well known that people who (think they) can exercise control over their environment themselves perceive less risk than those who cannot (Fischoff, Lichtenstein \& Slovic 1981; Slovic 1987; Vlek \& Keren 1992). This psychological mechanism could explain why middle managers perceive risk when their subordinates break rules, but not when they do so themselves. Performing operations offers the possibility of exercising control over the working environment personally, while enforcing implies dependence on others. It is also possible that such false sense of security occasionally results in taking irresponsible risks when breaking rules, although this is far from self-evident. Research has demonstrated that moderate unrealistic optimism results in more preventive behavior, rather than less (Otten 1998).

Second, it is possible that there are no risks involved when operational personnel break "impossible" rules, even though the enforcing supervisors think there are. Brun (1995) has found a convincing example of this possibility in his study on the ways high-tension thread electricians work. These electricians violated safety rules on purpose, even though they are exposed to life-threatening risks during their work on power pylons. Management 
strongly disapproved of these violations and accused the personnel of foolhardy and incompetent behavior. The electricians did have a good reason for it, however. Applying all the personnel safety devices decreased the visual contact with the working environment and hampered quick intervention in case something went wrong. By omitting certain safety devices, they retained visibility, and because of that, control over their own working environment. Brun's study shows that regulation may actually be dysfunctional. ${ }^{3}$

So, employees may occasionally deny risks when they break rules or may have a false sense of security when they do. However, sometimes there are simply no risks involved when they do. It is even possible that complying with rules increases risks instead of decreasing them. This shows that for rules are not good by definition, those who break them are not necessarily wrong. Though this conclusion is highly relevant for the determination of the blameworthiness of rule violations, it is definitely not new. Merton had already warned in 1957 that too much emphasis on bureaucratic discipline goes together with trained incapacity - the elevation of compliance with rules into a goal in itself, with the result that the original goal of the rule threatens to be lost out of sight. Or, as Kagan (1978; see also Knegt 1987) put it: the letter of the law can get in the way of its spirit. So, sometimes compliance with safety rules is risky, rather than breaking them. It is in these instances that it is problematic to label rule violations as human error.

\section{CONCLUSION AND DISCUSSION}

We have seen that in the coke factory three types of rule violations occur, only one of which can easily be labeled as human error. This is the type in which employees violate the rules because they think of complying as too much trouble or tiresome. These violations are blameworthy because this means that employees take a deliberate risk without being prevented in any way from doing so. The second reason is when external causes make it more difficult, if not impossible, for employees to comply with all the safety rules. The more obstructions people meet with, the less they can be blamed when they give in to those obstructions. The last reason for personnel to break the rules is if they think that complying is meaningless or even counterproductive. They cannot be blamed automatically for this type of violation either, for the simple reason that they are sometimes correct. If they are correct, there is even more reason to praise rule violators then to blame them. This is particularly the case when they break rules in a context where punishing is the standard. For this means they are prepared to control risk by breaking rules, when they are aware that they may suffer the consequences.

Apart from these moral implications, the findings also have instrumental value. They lead to the conclusion that the automatic response following manmade disasters to enforce severer is not always the most effective measure to prevent them. It is only so if rules are broken because of laziness. This 
type of violation is made less attractive by punishing rule violators. It is true that this is also the case if violations are caused by external causes, but, in this case, other measures are more obvious. Punishing is directed at the violator, while the cause of the violations lays somewhere else in this case. In these instances, better results can be expected from measures aimed at removing the factors that are hampering compliance than from more severe punishments for breaking the rules. If employees break the rules because they find them "impossible," it is surely important to be careful about tightening up enforcement. If the rules really are not any good, then this measure increases the chance of an accident, rather than reduces it. This leads to the conclusion that it is important to take the motives and causes of rule breaking into account when enforcing.

While this conclusion is at odds with the automatic reaction to disasters, it is perfectly in line with literature on enforcement. A punishment-centered or legalistic approach is seldom considered most effective under all circumstances (Hawkins 1990: 462; Johnstone 1999; Simpson 2002: 136, 152; Tenbrunsel \& Messick 1999, but see Pearce \& Tombs 1990, 1991). Inspectors should act as "politician," "consultant," or "policeman," depending on the willingness and the capacity of individuals or corporations to comply with rules (Kagan \& Scholz 1984). Severe sanctions should be reserved for the minority of "bad apples" that do not share regulatory goals (Makkai \& Braithwaite 1994). Inspectors also try to put this ideal into practice. They try to match their enforcement style with their image of their targets (Hawkins 1984; Hawkins \& Hutter 1993; Mascini 1999), though they are sometimes hampered against being coercive (Hawkins 1992; Wilthagen 1993) or not very particular about their methods (Braithwaite et al. 1994).

Why are the conclusions that rule violations are not always blameworthy and that tightening up enforcement is not automatically effective not easily drawn from disaster evaluations? The reason is that evaluators are inclined to reason back from the consequences of the rule violations. Disasters are easily raised as evidence that rules should be complied with. The violation of the rule itself is not the focus of attention. Another problem with judging rule violations which have led to a disaster is that the persons who have committed them are almost inevitably judged more severely than those whose violations did not cause a disaster. This is problematic because, by definition, both categories have committed these violations in uncertainty of the consequences of their acts. The unequal judgment of more or less similar acts is less likely when they are based upon possible, instead of actual, consequences. For such a judgment does justice to the uncertainty which is inherent to the choice of violating rules. This indicates the surplus value of risk research in comparison with disaster evaluations.

PETER MASCINI is assistant professor at the Faculty of Social Sciences of the Erasmus University of Rotterdam. He has published predominantly on the implementation of policy and on enforcement. 


\section{NOTES}

1. The Journal of Contingencies and Crisis Management 1998, 6(2) is dedicated exclusively to the second edition of Man-Made Disasters.

2. The average scores of the other seven goals were lower: enabling good collegial relationships (3.3), providing maximum employment (3.1), producing environmentally sound (3.0), providing optimal chances to learn and to gain experience (2.9), offering optimal promotion chances (2.5), ensuring optimal incomes (2.4), and making maximum profits (2.3).

3. Two other examples of counterproductive safety rules concern the relationship between administration and industry. The American Ministry of Transport wanted to force upon the truck industry to introduce an "improved" brake system (Kagan \& Scholz 1984: 89). The court struck down this rule, because of clear indications that this brake system was less dependable than the existing one and so increased the chance of truck accidents. The ministry unjustly stuck to the introduction of this rule, because it suspected the truck industry was opposed to this measure for purely economic reasons. In another example Baccus (1986) records that the maintenance and reparation of so-called multipiece truck wheels had caused tens of casualties and hundreds of wounded in the United States. The Ministry of Transport had not taken any measures to prohibit this type of bus and truck wheels because it refused to acknowledge that the maintenance procedures did not link up at all with the way maintenance was put into practice. This means that garage mechanics stuck to their habits because garages did not dispose of the required space and protection devices, and because most maintenance work was done in the open air.

\section{REFERENCES}

Alders, J. G. M. (2001) Rapport van de Commissie Onderzoek Cafébrand Nieuwjaarsnacht 2001 [Report of the Committee's Research into the Café Fire on New Year's Eve 2001]. Winschoten: Centrale Archief Selectiedienst.

Baccus, Melinda D. (1986) "Multipiece Truck Wheel Accidents and their Regulations." In Ethnomethodological Studies of Work, edited by Harold Garfinkel. London: Routledge \& Kegan Paul Inc.

Bourrier, Mathilde (1996) "Organising Maintenance Work at Two American Nuclear Power Plants," Journal of Contingencies and Crisis Management 4(2): 104-12.

Bovens, Mark (1998) The Quest for Responsibility: Accountability and Citizenship in Complex Organisations. Cambridge: Cambridge Univ. Press.

Braithwaite, Valerie, John Braithwaite, Diane Gibson, and Toni Makkai (1994) "Regulatory Styles, Motivational Postures, and Nursing Home Compliance," Law \& Policy 16: 363-94.

Brun, Jean-Pierre (1995) "Work Activity and Subjectivity: A Behind-the-Scenes Look at the Work of Linemen," Industrial Relations 50(1): 811-25.

De Koning, Petra, and Guido de Vries (2001) "Horeca lapt brandvoorschriften aan z'n laars: dansen in de vulkaan". ["Hotels and Restaurants Violate Fire Regulations: Dancing on the Volcano".] NRC-Handelsblad (6 January): 27.

Eijsvogel, Juurd (1996) "Clinton: strenge veiligheidsregels voor luchtvaart," ["Clinton: Tighter Safety Rules for Aviation"] NRC-Handelsblad (26 July): 1.

Fischer, Pim (1993) "Waarom verhalen werknemers na een bedrijfsongeval de geleden schade niet op hun werkgever?," ["Why Do Employees not Seek Compensation for their Loss from their Employer?"] Recht der werkelijkheid 14(1): 25-51.

Fischoff, Baruch, Sarah Lichtenstein, and Paul Slovic (1981) Acceptable Risk. Cambridge: Cambridge Univ. Press.

Gephart, Robert P., Jr. (1984) "Making Sense of Organizationally Based Environmental Disasters," Journal of Management 10(2): 205-25.

Haas, Jack (1977) "Learning Real Feelings: A Study of High Steel Ironworkers Reactions to Fear and Danger," Sociology of Work and Occupations 4(2): 147-70. 
Hawkins, Keith (1984) Environment and Enforcement: Regulation and the Social Definition of Pollution. Oxford: Clarendon Press.

Hawkins, Keith (1990) "Compliance Strategy, Prosecution Policy, and Aunt Sally: A Comment on Pearce and Tombs," British Journal of Criminology 30(4): 444-66.

Hawkins, Keith (1992) "FATCATS' and the Prosecution in a Regulatory Agency: A Footnote on the Social Construction of Risk." In Organizations, Uncertainties and Risk, edited by J. F. J. Short \& L. Clarke. Boulder, Colo.: Westview Press.

Hawkins, Keith, and Bridget M. Hutter (1993) "The Response of Business to Social Regulation in England and Wales: An Enforcement Perspective," Law \& Policy 15(3 July): 199-217.

Hutter, Bridget M. (2001) Regulation and Risk: Occupational Health and Safety on the Railways. Oxford: Oxford Univ. Press.

Johnstone, Richard (1999) "Putting the Regulated Back into Regulation," Journal of Law and Society 26(3): 378-90.

Jusek, Karin (2000) "Het graven in de mijn was in de huizen te horen," ["One Could Hear the Digging in the Mine in the Houses"] NRC-Handelsblad (10 January): 4.

Kagan, Robert Allen (1978) Regulatory Justice: Implementing a Wage-Price Freeze. New York: Russell Sage Foundation.

Kagan, Robert Allen, and John T. Scholz (1984) "The "Criminology of the Corporation' and Regulatory Enforcement Strategies.” In Enforcing Regulation, edited by K. Hawkins \& J. M. Thomas. Boston: Kluwer-Nijhoff.

Knegt, Robert (1987) "Rule Application and Substantive Justice: Observations at a Public Assistance Bureau," Netherlands' Journal of Social Sciences 23(2): 117-25.

Lipsky, Michael (1980) Street-Level Bureaucracy: Dilemmas of the Individual in Public Services. New York: Russell Sage Foundation.

Makkai, Toni, and John Braithwaite (1994) "The Dialectics of Corporate Deterrence," Journal of Research in Crime and Delinquency 31: 347-73.

Mascini, Peter (1999) Risico's in bedrijf: omgaan met gezondheidsrisico's op de werkvloer [Risks at Work: Handling Health Risks on the Shop Floor]. Rotterdam: Erasmus Universiteit Rotterdam.

Merton, Robert K. (1957) Social Theory and Social Structure. New York: The Free Press.

Oosting, Marten (2001) De vuurwerkramp. [The Firework Disaster.] Enschede: Commissie onderzoek vuurwerkramp.

Otten, Wilma (1998) "Onrealistisch optimisme," ["Unrealistic Optimism"] De Psycholoog 33(2): 46-53.

Pearce, Frank, and Steve Tombs (1990) "Ideology, Hegemony, and Empiricism," British Journal of Criminology 30(4): 423-43.

Pearce, Frank, and Steve Tombs (1991) "Policing Corporate 'Skid Rows': A Reply to Keith Hawkins," British Journal of Criminology 31(4): 415-26.

Perrow, Charles (1994) "The Limits of Safety: The Enhancement of a Theory of Accidents," Journal of Contingencies and Crisis Management 2(4): 212-20.

Pidgeon, Nick F. (1998) "Shaking the Kaleidoscope of Disasters Research: A Reply," Journal of Contingencies and Crisis Management 6(2): 97-101.

Pidgeon, Nick F., and Barry A. Turner (1997) Man-Made Disasters. Boston: ButterworthHeinemann.

Porte, Todd R. la (1994) "A Strawman Speaks Up: Comments on the Limits of Safety," Journal of Contingencies and Crisis Management 2(4): 207-11.

Porte, Todd R. la, and Gene Rochlin (1994) "A Rejoinder to Perrow," Journal of Contingencies and Crisis Management 2(4): 221-26.

Rasmussen, J., K., Duncan, and J. Leplat (1988) New Technology and Human Error, Wiley: Chichester.

Roberts, Karlene H. (1990) "Some Characteristics of One Type of High Reliability Organization,” Organization Science 1(2): 160-76. 
Roberts, Karlene H. (1993) New Challenges to Understanding Organizations. New York: Macmillan Pub. Co.

Roberts, Karlene H., Denise M. Rousseau, and Todd R. la porte (1994) "The Culture of High Reliability: Quantitative and Qualitative Assessment Aboard NuclearPowered Aircraft Carriers," Journal of High Technology Management Research 5(1): 141-61.

Sagan, Scott D. (1993) The Limits of Safety: Organizations, Accidents and Nuclear Weapons. Princeton N.J.: Princeton Univ. Press.

Sagan, Scott D. (1998) "Diane Vaughan (1996) The Challenger Launch Decision: Risky Technology, Culture and Deviance at NASA," Journal of Contingencies and Crisis Management 6(2): 113-14.

Schulman, Paul R. (1993) "The Negotiated Order of Organizational Reliability," Administration \& Society 25(3): 353-72.

Simpson, Sally (2002) Corporate Crime, Law, and Social Control. Cambridge Univ. Press: Cambridge.

Slovic, Paul (1987) "Perception of Risk," Science 236: 280-85.

Tenbrunsel, Ann E., and David M. Messick (1999) "Sanctioning Systems, Decision Frames, and Cooperation," Administrative Science Quarterly 44: 684-707.

Turner, Barry A. (1976) "The Organizational and Interorganizational Development of Disasters," Adminstrative Science Quarterly 21: 378-97.

Turner, Barry A. (1978) Man-Made Disasters. London: Wykeham.

Van der Lugt, Hans (1999) "Japanse overheid faalt als controleur en uitvoerder". ["Government of Japan Fails as Inspector and as Implementor".] NRC-Handelsblad (4 October): 5.

Vaughan, Diane (1996) The Challenger Launch Decision: Risky Technology, Culture, and Deviance at NASA. Chicago: Univ. of Chicago Press.

Vlek, Charles A. J., and Gideon Keren (1992) "Behavioral Decision Theory and Environmental Risk Management: Assessment and Resolution of Fur 'Survival' Dilemmas," Acta Psychologica 80: 249-78.

Weick, Karl E. (1987) "Organizational Culture as a Source of High Reliability". California Management Review 29(2 Winter): 112-27.

Weick, Karl E. (1997) "Diane Vaughan (1996) The Challenger Launch Decision: Risky Technology, Culture, and Deviance at NASA," Administrative Science Quarterly 42(2): 395-401.

Weick, Karl E. (1998) "Foresight of failure: an appreciation of Barry Turner," Journal of Contingencies and Crisis Management 6(2): 72-75.

Weick, Karl E., and Karlene H. Roberts (1993) "Collective Mind in Organizations: Heedful Interrelating on Flight Decks," Administrative Science Quarterly, 38(September): 357-81.

Weick, Karl E., Kathleen M. Sutcliffe, and David Obstfeld (1999) "Organizing for High Reliability: Processes of Collective Mindfulness," Research in Organizational Behavior 21: 81-124.

Wildavsky, Aron (1988) Searching for Safety. New Brunswick: Transaction.

Wilthagen, T. (1993) Het overheidstoezicht op de arbeidsomstandigheden: Een onderzoek naar het functioneren van de Arbeidsinspectie [The Inspection of WorkingConditions: A Research on the Operating of the Labor Inspection]. Groningen: Wolters-Noordhoff.

Wittenberg, Dick (1997) "Major laat slachthuizen onderzoeken," ["Major Decides to Investigate Slaughter Houses”] NRC-Handelsblad (12 March): 5. 